\title{
A CORRUPÇÃO EM PERSPECTIVA LATINO-AMERICANA: A FETICHIZAÇÃO DO PODER NA OBRA POLÍTICA DE ENRIQUE DUSSEL
}

\author{
Daniel Pansarelli ${ }^{1}$ \\ Bruno Reikdal Lima
}

\begin{abstract}
Resumo: O presente artigo tem por objetivo apresentar o tema da corrupção, a partir da filosofia política de Enrique Dussel. No marco dos movimentos críticos que emergem no chamado Sul Global, a produção teórica de Dussel busca desenvolver uma estrutura que possibilite a crítica ao que denomina como fetichização do poder. Esse conteúdo é abordado como fundamento da corrupção das instituiçôes que, despercebido pela tradiçấo filosófica moderna, implica uma teoria política que legitima o poder corrompido. $\mathrm{Na}$ argumentação aqui concretizada, será exposta a arquitetônica da política dusseliana, distinguindo os conceitos de potentia e potestas. Estes, por sua vez, permitem a diferenciação entre o uso delegado do poder e a execução corrompida do poder. Em seguida, será explicitado o movimento que Dussel assume da crítica de Marx à economia política, para, então, indicar o conteúdo material a partir do qual a constituição crítica de uma nova teoria política deve ser desenvolvida - inspirado em experiências políticas latino-americanas.
\end{abstract}

Palavras-chave: Fetichização do poder. Potentia. Potestas. Corrupção. Enrique Dussel.

\section{INTRODUÇÃo}

As relações dialógicas entre autoras e autores latino-americanos e africanos - sejam estes situados no próprio continente, sejam diaspóricos -,

\footnotetext{
${ }_{1}$ Professor no Programa de Pós-Graduação em Filosofia da Universidade Federal do ABC (UFABC), São Paulo, SP - Brasil. (D) https://orcid.org/0000-0003-0881-5493. E-mail: pansarelli@gmail.com.

2 Doutorando em Economia Política Mundial pela Universidade Federal do ABC (UFABC), São Paulo, SP - Brasil. (D) https://orcid.org/0000-0003-1990-0554. E-mail: bruno@reikdal.net.
}

https://doi.org/10.1590/0101-3173.2022.v45esp.17.p339 
intensificadas nos últimos anos, têm se mostrado especialmente frutíferas na identificação de temáticas filosóficas comuns, pertinentes às realidades sociais de ambos os continentes. $\mathrm{O}$ desvelamento da designação classificatória atribuída aos países, como subdesenvolvidos ou em desenvolvimento, tem possibilitado a explicitação de questóes sociais presentes, talvez, em todo o chamado Sul Global, e impulsionado a reflexão filosófica integrada, em diversos âmbitos.

Do amplo temário comum, destacamos neste artigo um deles, cuja tradição na Filosofia Política remonta à Antiguidade Clássica, mas que ganha contornos peculiares nas leituras feitas desde a América Latina. A questáo da corrupção pode ser tomada como uma espécie de constante ou universal, invariavelmente presente no conjunto dos países que constituem o Sul Global. E, em todos os casos, há um complicador peculiar, em relação aos estudos eurocêntricos tão abundantes nos países do Sul: a corrupção é parte de um processo global de exploração internacional, não se limitando a uma questão de poder interna a cada país. Dito de outro modo, a história colonial estabelecida desde o início da Modernidade, tal como amplamente estudada por Enrique Dussel (1994), Severino Ngoenha (2003) ou José Castiano (2010), dentre tantos outros, desenvolveu uma cultura da corrupção submissa, nos países colonizados, tornando a corrupçáo uma espécie de fenômeno constitutivo de sua própria identidade nacional, algo tolerável, aceitável, de certo modo, normal. Não se trata, portanto, da corrupção das instituiçôes ocasionada pela própria disputa dialética do poder pelos setores internos da sociedade, tal como discutido por Platáo, Aristóteles ou Maquiavel, para mencionar apenas alguns dos clássicos. No caso dos países do Sul, esses setores da sociedade local são direta e intencionalmente influenciados, provocados, por forças estrangeiras, por seus colonizadores. A corrupçáo é parte do projeto, e não um desvio dele.

Nesse contexto, trazemos no presente artigo uma reflexão sobre a questão da corrupção na perspectiva da filosofia latino-americana, mais especificamente na obra política, recente, de Enrique Dussel. O autor, o qual constituiu sua ampla obra ética entre os anos de 1992 e 1998, desde então tem construído a sua Política da libertação (2007, 2009), oferecendo elementos para o presente estudo. Retomaremos, na primeira parte do artigo, a relação entre três conceitos do pensamento dusseliano que são chaves para compreender a questão da corrupçáo, a saber, as noçóes de potentia, potestas e fetichização. A seguir, procuraremos demonstrar como a fetichização do poder é o fundamento da corrupçáo, considerando nessa análise a complexidade específica das relaçóes de poder nos países do Sul, com sua história colonial. 
Nosso esforço com essa reflexão é o de oferecer uma análise da questão da corrupção condizente com a realidade histórica dos países colonizados, de modo que ela possa, ao lado dos estudos clássicos já consolidados, permitir às sociedades contemporâneas que melhor enfrentem suas próprias questôes sociais emergentes.

\section{ARQuitetôNICA Do PODER}

O Método para una filosofía de la liberación (1974), desenvolvido por Enrique Dussel ainda no momento em que começava a estruturar sua obra filosófica, preconiza uma análise dialética da realidade, em um sentido peculiar, a que o autor chama de analética. Esse método, grosso modo, consiste em tomar como ponto de partida para o movimento a exterioridade do objeto que se pretende estudar. Diferentemente da dialética hegeliana, em que a afirmação é o primeiro ponto do movimento, Dussel propóe que partamos do negado, do excluído, daquele ou daquela que constitui a exterioridade em relação ao que se pretende estudar. Embora o Método tenha sido publicado pelo autor, em meados dos anos 1970, aparentemente ele permanece ativo em seus recentes estudos sobre a Política.

$\mathrm{Na}$ arquitetônica da Política da Libertação, tal como desenvolvida por E. Dussel, o poder é expresso de duas formas distintas, ainda que possua apenas uma e a mesma fonte. Potentia e potestas são as duas faces do poder. A primeira, potentia, é determinada pelas próprias condiçóes necessárias para a produção e reprodução da vida, a saber: a vontade-de-vida, o consenso entre as pessoas que constituem a comunidade e a organização de projetos factíveis. Trata-se propriamente do poder originário das comunidades políticas - e é originário, porque seu exercício é condição necessária para a vida. Nas palavras do autor,

[...] a potentia é o poder da comunidade política "mesma"; é (a) a pluralidade de todas as vontades (momento material) ou da maioria hegemônica, (b) unida pelo consenso (momento formal discursivo), e que (c) conta com os meios instrumentais para exercer seu poder-pôr mediaçóes (momento das mediações, da factibilidade). São, portanto, por agora, três determinaçóes essenciais do poder como potentia. (DUSSEL, 2009, p. 60). ${ }^{3}$

${ }^{3}$ É livre a tradução dos textos de Enrique Dussel referidos em língua espanhola. 
Esse é o que se poderia chamar de poder em si, por ser originário e necessário à propria existência de uma comunidade política. Toda comunidade política emana potentia, e nenhuma comunidade política poderia se formar sem ela. Toda e qualquer organização do poder, sua institucionalização, só poderia se dar posteriormente à sua existência e à existência da própria comunidade política. Ela, a potentia é o "[...] fundamento e ponto de partida desde o qual podem ser constituídas as instituiçóes e implementados o político (enquanto conteúdo) e a política (enquanto atividade).” (LIMA, 2018, p. 156).

Embora se trate do poder originário ou, talvez, exatamente por isso, a potentia carrega em si a característica de sua não realização. Ela guarda a força originária, mas não é, ainda, a expressão realizada, efetiva, do poder. Explicita Dussel que

[t]udo o que se chame "político" terá que se fundar em última instância nessa potentia. Mas, enquanto tal e se não for determinada de nenhuma maneira (quer dizer, heterogeneamente institucionalizada), permaneceria "vazia", como um "nada" político: pura potentia, sem razáo alguma, sem performatividade. A comunidade política, antes de todo agir político, é pura potentia. (DUSSEL, 2009, p. 60).

A vontade-de-vida, então, direciona a comunidade para a construção dos consensos necessários, sem os quais não seria possível a produção e a reprodução das condições necessárias para a vida da própria comunidade. Este segundo momento, derivado da potentia originária, é a potestas: a efetivação, a organização, a execuçáo do poder. Para a vida em comunidade, algum nível de institucionalização é requerido, e é na execução do poder como potestas que ela pode se realizar:

O poder originário (potentia) enquanto tal é indeterminado (ainda não-algo) e como tal sem "falta" alguma, mas também sem existência real nem empírica. $\mathrm{O}$ simples passo à mínima institucionalização ou organização de alguma função heterogênea de um membro com respeito ao outro produz já uma determinação [...] e começa a possibilidade da existência real, mas, ao mesmo tempo, da possibilidade da "distância" do representante em relaçáo ao representado, da institucionalização em relação ao institucionalizado, do exercício delegado do poder (potestas) que não é já simplesmente o poder consensual "desde baixo" mesmo (potentia). (DUSSEL, 2006, p. 27). 
A potestas é, portanto, a expressão mais desenvolvida do poder, sua expressão por meio da força das instituiçóes, necessárias à existência da vida em comunidade, da vida política. Daí o imperativo, segundo o método analético, de se iniciar pela potentia a compreensão do que seja o poder: ela é a origem, contudo, não a expressão do poder que está contida e executada nas instituições políticas. É ela, a potentia, a origem, mas também a exterioridade do poder. $\mathrm{E}$, não raro, é a vítima, controlada, do próprio poder instituído. Seguindo o método dusseliano, referido no primeiro parágrafo desta seção, a melhor compreensão da potestas, em perspectiva latino-americana, passa pela tomada da potentia como início do movimento dialético.

O desdobramento da potentia em potestas é necessário, previsível, uma consequência do fluxo normal do desenvolvimento da vida em comunidade. Mas é da possibilidade da cisão entre ambas, após desenvolvida a potestas, que surge a origem da possibilidade da corrupçâo. Quando a potestas, como poder institucionalizado, se fecha nos sentidos que adquire o poder, dentro do contexto das próprias instituiçôes, ou seja, quando o poder institucionalizado rompe com os motivos de sua expressão originária, ocorre precisamente aquilo que Dussel chama de fetichização: o encerramento de um sistema em torno de si mesmo, o desligamento desse sistema com sua exterioridade.

Reside aí uma situação incontornável ao desenvolvimento da vida em comunidade e, ao mesmo tempo, temerária:

A necessária institucionalização do poder da comunidade, do povo, constitui o que denominaremo potestas. A comunidade institucionalizada, quer dizer, tendo criado mediaçóes para seu exercício possível, cinde-se da mera comunidade indiferenciada. Essa cisão entre potentia e potestas (com Spinoza e Negri, mas ao mesmo tempo para além deles), entre: a) o poder da comunidade política como sede, origem e fundamento (o nível oculto ontológico) e b) a diferenciação heterogênea de funçóes por meio de instituições que permitem que o poder se torne real, empírico, factível, que apareça no campo político (como fenômeno), é necessária, e marca a apariçáo imaculada da política, sendo ao mesmo tempo o perigo supremo como origem de todas as injustiças e dominaçóes. Graças a essa cisão, todo serviço político será possível, mas também toda a corrupção ou opressão começa sua corrida incontrolável. (DUSSEL, 2006, p. 30).

Nessa leitura da arquitetônica do poder, procedida por Dussel devemos ter claro que o esforço do autor, nesse momento, se direciona ao desvelamento da arquitetônica, do esquema estruturante, e não da prática 
cotidiana; é, nesse sentido, um esforço de desvelamento - a possibilidade da contradição opressora se explicita. Por um lado, "[...] a potentia é o poder em-si, a potestas é o poder fora-de-si (não necessariamente, entretanto, o parasi, como retorno)" (DUSSEL, 2006, p. 29), reafirmando a precedência da potentia sobre a potestas e o papel da primeira como força originária do poder político. Todavia, ao mesmo tempo, "[...] o exercício do poder sempre é um momento da potestas, ou das funções fixadas pelas instituiçôes." (DUSSEL, 2006, p. 31). Essa força originária não se realiza sem que haja a aplicação institucional do poder, sendo, portanto, refém de sua execução. Ao passo em que a execução do poder não precisa, condicionalmente, guardar compromisso ético com a vontade consensual de sua força originária, cria-se a possibilidade da fetichização, nesse caso, uma espécie de protocorrupção.

\subsection{ENTRE O PODER OBEDIENCIAL E SUA FETICHIZAÇÁO}

Se a explicitação da arquitetônica do poder político é um exercício de desvelamento, a sua execução prática se mostra sempre na expressão de potestas. É sempre por meio das instituiçóes que se exercita o poder. Fora-de-si é o único lugar no qual se pode realizar o poder em-si. Portanto, a separaçáo nesses dois momentos é justamente um exercício filosófico de elucidação da estrutura de poder, que, seguindo um método próprio desenvolvido para a filosofia latino-americana, permite a melhor compreensão e mesmo o eventual julgamento de seu sentido ético. No âmbito teórico, reafirmar a potentia como poder originário, reafirmar o consenso construído na comunidade política como meio para sua execução, como potestas, enseja oferecer um critério (a motivação da potentia) para o julgamento ético da execução (potestas) do próprio poder. Entretanto, a despeito do esforço teórico de desvelamento arquitetônico, o poder é um e o mesmo:

Não se pense que essa cisáo ontológica entre potentia e potestas se produz como dois extremos "limpos", claros, perfeitamente diferenciados [...]. Com efeito, o poder está disseminado em todo o corpo político. Tanto nas diversas articulaçóes comunitárias (na base, a diversidade da potentia) como de instituiçóes das mais variadas que se exercem de forma delegada e se apoiam umas sobre outras (a diversidade da potestas). (DUSSEL, 2009, p. 63). 
E continua:

De fato, o poder político se encontra disperso em todo o campo político e nos sistemas concretos, na comunidade política e em todas as comunidades, associações, organizaçóes subalternas, como potentia, que se implementa regenerando continuamente todas as atividades, ideologias, saberes das diversas conglomeraçóes sociais [...] e ainda da sociedade política, como expressáo da energia desde baixo para cima, que emana da pluralidade das vontades unidas por diversos tipos de consenso; e ainda como potestas, que se expande também em todas as instituiçóes (de cima para baixo), enchendo-as de vontade de participação, de fraternidade com respeito ao serviço próprio do exercício delegado do poder [...] ou, pelo contrário, desenvolvendo técnicas, mecanismos, epistemologias, instituiçóes de controle, de domínio, de debilitação da potentia. (DUSSEL, 2009, p. 63).

Mas essa potentia "que se implementa", uma vez implementada, não é mais reconhecida. Ela cede espaço, como se o poder implementado, visto que já está implementado, não necessitasse responder a uma força originária. Essa potentia fica velada pelo poder perceptível em sua execução. Afinal,

[...] todo exercício do poder é institucional, porque o poder da comunidade como potentia em-si não é um momento empírico inicial no tempo, senão um momento fundamental que permanece sempre no ato debaixo das instituiçóes e açóes (debaixo da potestas). Quando se fala, então, de "exercício do poder", significa que se atualiza em alguma de suas possibilidades institucionais. (DUSSEL, 2006, p. 31).

$\mathrm{Na}$ execução do poder, por conseguinte, nunca está presente de forma imediata a sua força originária, ainda que ela permaneça sempre existente. A potentia ali está, mas invariavelmente velada. A instituição, como locus de sua execução, funciona ao mesmo tempo como mediadora da força originária e como a sua realização. Reside justamente nessa mediação o espaço da sua virtude ou do seu desvirtuamento ético.

Como meras mediaçóes, as instituiçóes não são, por si mesmas, nem éticas, nem antiéticas. Nessa análise arquitetônica, são apenas espaços para a execução do poder. Fato é que essa execução pode "zelar pelas" ou pode "velar as" motivaçóes que originaram tal poder. No primeiro caso, de zelo pelas motivaçóes originárias, temos a aplicação do poder obediencial ou do exercício delegado do poder, situação na qual se vale da instituição exatamente 
como meio necessário à organização comunitária, política, para viabilização da execução do poder, em favor de sua motivação potential.

No outro caso, invariavelmente mais comum na história colonial dos países do Sul Global, a mediação da instituição serve justamente para o oposto: velar, esconder a motivação originária, a fim de que ela não se faça aparente no momento da execução do poder. É, em sentido marxiano, o feitiço da mediação que oculta, que fetichiza. O que, em sentido dusseliano, possibilitará a aplicação fetichizada do poder, ou seja, a sua aplicação em função de valores internos à própria instituição, não mais considerando sua exterioridade (a potentia). Trata-se do fechamento, do encerramento da instituição em si mesma, da apropriação do poder para outras motivaçóes, distintas das originárias. É a construção de uma espécie de "lógica interna”, falaciosa por princípio, uma vez que a própria instituição só existe em função do poder originário, que lhe é externo. Contudo, de posse do poder delegado, a instituição pode se fetichizar num movimento autorreferente e excludente. Trata-se do primeiro exercício da corrupção:

A autorreferência, como última instância da potestas, é o exercício fetichizado ou corrompido do poder político. Quando o ator político, que exerce o poder institucionalizado (seja um rei, seja um representante, seja uma elite política), afirma-se a si mesmo como sede da soberania, da autoridade ou como última instância do exercício do poder para seu benefício, ou de seu grupo, sua classe ou sua facção, quer dizer, quando se desvia do exercício obediencial à autoafirmação do poder desde si, origina-se ontologicamente a fetichização, a corrupção, a desnaturalização do poder como dominaçáo, despotismo, tirania. (DUSSEL, 2009, p. 12).

Nesse ponto, faz-se necessário pensar a especificidade dessa estrutura corrupta e corruptiva do poder, no contexto histórico e social do Sul Global. Conforme o próprio Dussel já havia demonstrado, em uma obra esquemática, bastante anterior à formulação mais definitiva de sua Política da Libertaçâo, a autorreferência das instituiçôes nos países colonizados não é meramente local, pois comporta elementos da colonialidade imperialista que necessariamente influiu, por séculos, sua constituiçấo e, consequentemente, a constituição de suas instituiçóes. O autor já apontava que, desde uma perspectiva dos países dominados, "[...] no nível internacional ou mundial a alienação dos povos periféricos se produz pelo imperialismo", e que, 
[...] na essência do ethos da dominação imperial, encontra-se a certeza disciplinada do burocrata [...] que cumpre diariamente seus deveres pátrios e religiosos com escrupulosa consciência moral de fazer avançar o caminho da civilização, da cultura, da democracia, da liberdade... por meio do assassinato, da chantagem, da corrupçáo, da exploração, da fome, do sofrimento da periferia. (DUSSEL, 1977, p. 92-93).

O próprio projeto civilizatório, ocidental e moderno, realizado desde uma perspectiva eurocêntrica, se desenvolveu por meio "[...] de um necessário processo de simplificação por 'racionalizaçáo' do mundo da vida." (DUSSEL, 1998, P. 60). O desenvolvimento das instituiçôes nos países colonizados, portanto, ocorre desde uma dupla origem: por um lado, a força do poder originário, sua potentia; por outro, uma lógica burocrática, cuja razão orientadora é eurocêntrica, não condizente e nem respeitosa às comunidades políticas que geram sua potentia. Como resultado desse processo, tem-se como regra que a mediação institucional para execução da potestas se efetiva como fetichização, e não como poder obediencial. Chegamos, assim, à corrupção como inerente. É o mais provável resultado da gestão feita por uma razão alheia, estranha, sobre um poder comunitário local. Nesse contexto, a aplicação obediencial do poder torna-se exceção a uma regra, que é geral: a corrupção.

\section{SOBRE A CORRUPÇÃo COMO FETICHIZAÇÁO}

Conquanto a arquitetônica desenvolvida por Dussel evite o rechaço a qualquer tipo de instituição ou processo de institucionalização, ela também revela a necessidade permanente de se institucionalizar. Isso não implica, todavia,a aceitação ou a manutenção de toda e qualquer instituição. Esta passa a ser avaliada a partir da capacidade de atender ou náo à comunidade que a desenvolve como mediação para execução do poder. Quando a potestas atua tendo como referência atender às necessidades da comunidade que a estabelece, cumpre sua função fundamental. Por outro lado, quando não atua mais desde sua base material, mas a oculta, atuando de modo autorreferente, ela se corrompe fundamentalmente.

Dessa forma, Dussel avança sobre a tensão das determinações políticas, afirmando que,

[...] em uma realidade empírica concreta, imperfeita, corrigível, contingente $[. .$.$] toda distância entre representante/representado (como da$ potestas/potentia) prestará motivos para equívocos, opacidades, distorçóes, 
dominações possíveis. De todo modo, é inevitável, a institucionalização diferenciada póe um "ente" (Dasein) ou mediaçáo entre os muitos (vontades consensuais da comunidade política) e os poucos (os atores do Estado e outras instituiçốes necessárias). (DUSSEL, 2009, p. 285).

Quando as instituiçóes tomam a si mesmas como sede ou detentoras do poder, ocultando e causando uma cisão com a comunidade que as institui, efetivam o processo de fetichização. Para desenvolver o aparato crítico que revela as possibilidades positivas e negativas da cisão entre potentia e potestas, do exercício delegado do poder e da execução corrompida do poder, Dussel procura operar em um movimento semelhante ao que encontra em Marx. $\mathrm{Na}$ interpretação do filósofo latino-americano, a crítica marxista da economia política é desenvolvida

[...] por meio da construção de um novo sistema de categorias econômicas, cuja ordem estava regida pelo método que partia da exterioridade do sistema, ou do excluído oculto (o trabalho vivo e, a partir dele, o maisvalor), para descrever as categorias fenomênicas fundadas mais superficiais (como as de valor de troca ou lucro). O fundado é o que aparece. Se não se funda adequadamente o fenômeno que se apresenta, ele se fetichiza. $\mathrm{O}$ lucro que diz advir do capital (e não do trabalho vivo) se fetichiza. Quer dizer, pretende se fundar em si mesmo (no capital), cortando toda relaçáo com seu fundamento (o trabalho vivo que é a fonte criadora do mais-valor). (DUSSEL, 2009, p. 11-12).

O ponto de partida que torna possível a crítica da economia política, sob essa perspectiva, é o "trabalho vivo", o qual, para Marx, nos Grundrisse, aparece "[...] não como objeto, mas como atividade [...], como fonte viva do valor.” (MARX, 2011, p. 230). Por outro lado, a estrutura teórica que justifica e legitima a exploração da atividade produtiva de trabalhadores e trabalhadoras pelo capital, destacada n'O Capital como uma teoria "[...] que não se importa com o tempo de vida da força de trabalho" (MARX, 2017, p. 338), não toma como ponto de partida seu fundamento real, vivo, mas um dos resultados instituídos no processo produtivo. A vida da comunidade de trabalhadores é ocultada, apagada e mesmo violentada por uma determinada instituição econômica que atua contra ela mesma.

Ao se revelar o fundamento de todo valor e toda produção de valor, portanto, é possibilitada a crítica à coordenação da divisão social do trabalho, que, para Marx, produz “[...] não apenas a debilitação da força humana de 
trabalho, que se vê roubada de suas condiçóes normais, morais e físicas, de desenvolvimento e atuação. Ela produz o esgotamento e a morte prematuros da própria força de trabalho." (MARX, 2017, p. 338). O resultado do processo produtivo tomado como a base de todo o sistema econômico promove uma inversão, na qual o conteúdo vivo, o sujeito da produção, é negado e passa a atuar não para produzir ou reproduzir a vida, porém, na manutenção do acúmulo e ganhos de capital. Ao proceder à distinção entre potentia e potestas e a determinação da referência na comunidade de vida, Dussel buscou realizar um exercício comparável ao que Marx faz, no campo da economia política. Contudo, na produção dusseliana, trata-se da "[...] filosofia política, guardando a analogia epistêmica necessária.” (DUSSEL, 2009, p. 12).

O resultado dessa transposição crítica é colocar em questão os sistemas que justificam elegitimam a execuçáo corrompida do poder, quando tomam uma determinada mediação para o exercício do poder como fundamento, ponto de partida, como a sua própria sede ou fonte. Dessa maneira, se temos no campo político uma relaçáo semelhante à do campo econômico, na qual o produto domina o sujeito que a produziu, quando as teorias políticas náo criticam o ocultamento ou encobrimento da potentia que instituem, assumindo a potestas como fundamento do poder, incorrem no desenvolvimento de um sistema teórico fundamentalmente corrompido. Tal sistema está na base constitutiva das instituições estruturantes dos países historicamente colonizados.

Sem a devida avaliação crítica do fundamento e da execução do poder, abre-se a possibilidade para produçóes teóricas que justifiquem a atuação dominadora e violenta de instituiçôes, no esforço de manterem a si mesmas na posição de execução de poder, sem referência à comunidade viva que as institui (e, potencialmente, destitui). Reduz-se o poder ao seu caráter negativo, como exemplarmente expresso na concepção política de Weber, para quem é "[...] absolutamente essencial para qualquer associação política recorrer à violência bruta dos meios coercitivos em face de inimigos externos, bem como aos inimigos internos. Somente esse recurso mesmo à violência é que constitui uma associação política em nossa terminologia." (WEBER, 1997, p. 166).

O resultado último decorrente da concepção weberiana para a organização da sociedade moderna é reduzir o Estado a "[...] uma associação que pretende o monopólio e o uso legítimo da violência, e não pode ser definido de outra forma." (WEBER, 1997, p. 166). Legitima-se a violência e a dominação como conteúdo propriamente político. A instituição política moderna por excelência, o Estado, aparece pretensamente como detentora do 
poder, apresentada sob a figura do Leviatâ, imagem que Dussel utiliza como um monstro que "[...] nasce quando a comunidade perdeu o poder político (quer dizer, quando a comunidade política foi dominada e o poder suplantado por um fetiche)." (DUSSEL, 2009, p. 202). Desse modo, a instituição política moderna é revelada como fundamentalmente corrompida, assim como sua legitimação na teoria política moderna, a qual se constitui como um sistema totalizado, fechado sobre si mesmo, que reduz o conteúdo político a seu caráter negativo.

\subsection{CONTRA O FUNDAMENTO DA CORRUPÇÁO}

Contra a mera aceitação da corrupção institucional, a efervescência política latino-americana guarda grande importância em movimentos e experiências que colocam em questáo não apenas a reprodução social moderna e seus processos de fetichização, como as teorias que legitimam a manutençáo dessas relaçôes. Analisando a questão, é o próprio Dussel que aponta, por exemplo, o caso do Exército Zapatista de Libertação Nacional (EZLN), o qual, em sua organização política e produção ideológica, se coloca contra qualquer forma social em que "[...] os que mandam, mandam mandando", no intuito de estabelecer relaçóes sociais em que "[...] os que mandam, mandem obedecendo" (MARCOS, 2013). Na reflexão procedida por Dussel a esse respeito, observa-se que,

[q]uando, no EZLN, os zapatistas expressam que não é o mesmo que: (a) "os que mandam, mandam mandando" (que em nossa terminologia será expressão da potestas negativa ou o poder institucionalizado que, sendo delegação do exercício que vem da comunidade política, se fetichiza [...] pretendendo soberania por si mesma); do que (b) "os que mandam, mandem obedecendo" (que significa que a potestas se funda na potentia), nos dáo claras indicaçóes para saber pensar a essência do poder político, contra o modelo moderno do poder como dominação. (DUSSEL, 2009, p. 24).

O poder, fundamentalmente, é realização da vontade-de-vida de uma comunidade, que visa a produzir e reproduzir sua vida. Para tal, cria mediaçóes que tornem viáveis os projetos que auxiliam na realização desse princípio necessário. A experiência zapatista aparece, nesse sentido, como referência por pretender o desenvolvimento de instituiçóes que tomem o caráter positivo do poder, o uso das mediaçóes em favor da vida da comunidade que as institui, 
como ponto de partida. Trata-se, como sintetiza Dussel, do "uso obediencial do poder a favor da comunidade", o qual instaura "[...] um círculo entre a potentia que alimenta a potestas, e esta que serve à primeira. Assim, o poder cobra seu sentido pleno e é usado segundo sua própria natureza." (DUSSEL, 2009, p. 137).

O desenvolvimento de uma produçáo teórica que dê conta de criticar o poder fetichizado, não assumindo sem qualquer suspeita da redução do poder, tem como intuito contribuir na organização política do continente latino-americano (e, analogamente, de todo o Sul Global), que, para Dussel, vivenciou "[...] uma certa 'Primavera política" (DUSSEL, 2006, p. 7), com o surgimento e fortalecimento de novos movimentos sociais e de governos que tinham como base organizaçóes militantes e populares. No ensejo desses fenômenos políticos, próprios do continente, o filósofo latino-americano avalia que a "[...] nova teoria não pode responder aos pressupostos da modernidade capitalista e colonialista dos últimos 500 anos.” (DUSSEL, 2006, p. 7). Desse modo, deve-se ter em conta que

[p]assar da responsabilidade democrática política de exercer um poder obediencial não é tarefa fácil; é intrinsecamente participativa, sem vanguardismos; havendo aprendido do povo o respeito por sua cultura milenar, por suas narrativas míticas dentro das quais desenvolveu seu próprio pensamento crítico, suas instituições que devem ser integradas a um novo projeto. (DUSSEL, 2006, p. 8).

Estipula-se, por conseguinte, que a própria base material para a produção de uma nova teoria política, crítica e que busca não fetichizar seu conteúdo político, são as comunidades locais - no nosso caso, as latinoamericanas, todavia, analogamente, as africanas e dos demais continentes suas produçốes e dinâmicas. Assim, para o desenvolvimento da nova teoria, Dussel (2006, p. 61) destaca a necessidade de se analisar certos processos sociais, como o de ascensão dos movimentos cocaleiros e a governança de Evo Morales, na Bolívia, da organização popular da revolução sandinista na Nicarágua e do próprio movimento zapatista do EZLN, no México, enquanto organizaçóes capazes de incluir dimensóes culturais e formas políticas das comunidades ancestrais. Ancorados nas comunidades historicamente negadas pelo poder corrompido, os novos projetos políticos devem, conforme Dussel, 
[...] considerar se as instituiçôes servem de verdade para satisfazer as reivindicações da comunidade, do povo, dos movimentos sociais. Se náo servem, devem ser transformadas. H. Chávez muda a Constituição, no início do exercício delegado do poder; Evo Morales também. Quer dizer, o pacote das instituiçóes estatais (potestas) deve ser desatado, mudar sua estrutura global, conservar o sustentável, eliminar o injusto, criar o novo. (DUSSEL, 2006, p. 151).

A criação do novo conteúdo político entra no processo crítico da cultura hegemonizada que se instaura na dominação colonial. $\mathrm{O}$ desenvolvimento de estruturas políticas fundamentalmente corrompidas e institucionalizadas, em um contexto de dependência, sob um projeto moderno de dominação e exploração. O deslocamento do ponto de partida para as comunidades negadas nas dinâmicas do exercício fetichizado do poder compóe, em contexto amplo, processos de libertação: movimento constante de crítica às estruturas dominadoras, tendo como intuito a garantia das condiçóes para que a vida das comunidades se produza, reproduza e desenvolva. Uma volta aos valores da potentia, em favor de sua realização como poder obediencial, na potestas.

Não se trata, portanto, de partir da crítica às açôes, em acordo ou desacordo com as regras internas de instituiçóes vigentes. Mas, antes, de criticar o próprio fundamento dessas instituiçôes e das produçóes teóricas que partem de sua existência e funcionamento para compreender o conteúdo do político e a atividade política. Sem esse deslocamento, o tema da corrupção é reduzido aos desvios dos regimentos das instituiçóes e à exigência do cumprimento de suas determinaçóes legais. Contudo, como apresentado, instituiçóes fundamentalmente fetichizadas, ou seja, fundadas em si mesmas, sem irrestrito respeito à comunidade que a sustenta e pressupóe, não podem ter como referência para a crítica da corrupção seu próprio funcionamento e execução do poder. Nesse sentido, a corrupção, sob a perspectiva da filosofia da libertação latino-americana, não pode ter sua análise reduzida aos acordos legais e às normas políticas estabelecidas, pois o conteúdo que fundamenta a própria regulação e manutenção das instituiçóes que os vaticinam deve estar sob a suspeita de ser fetichizado.

\section{Consideraçóes FinaIs}

Ao realizar, na Filosofia Política, movimento análogo ao procedido por Marx no seu estudo da Economia, Dussel oferece elementos para uma leitura 
e crítica da política que sejam mais pertinentes à realidade sócio-histórica dos países da América Latina e outros, marcados pela colonização. Trata-se de um processo filosófico de desvelamento da fetichização do poder, a fim de que se possa melhor perceber suas motivaçôes originárias.

É com esse objetivo que o autor, num exercício didático, demonstra os elementos constitutivos da arquitetônica do poder: a potentia como sua força originária e não realizada; e a potestas, como realização do poder, mediado pelas instituiçôes, distante, portanto, de sua origem. Nesse ponto, explicita-se o duplo entendimento das instituiçóes que são, por um lado, imprescindíveis à realização do poder e, por conseguinte, à própria manutenção da existência das comunidades políticas; mas, por outro lado, são a origem da possibilidade da corrupçáo do próprio poder. Compreendida no contexto peculiar da constituição histórica dos países latino-americanos, essa estrutura leva à condição de normalização da corrupção. A história colonial dos países imprime às suas instituiçôes características de uma corrupção submissa, de modo que a realizaçáo do poder fetichizado, corrompido, se torna regra, enquanto a realização do poder obediencial acaba ganhando contornos de rara exceção.

Entretanto, o mesmo esforço de apropriação do movimento marxista e de sua aplicaçáo, no âmbito da Filosofia Política, possibilita que, a partir os elementos oferecidos por Dussel, busquemos encontrar nas próprias comunidades políticas latino-americanas - e, analogamente, africanas elementos para uma superação da estrutura corrompida, cuja crítica se estabeleceu ao longo deste artigo. Reconhecer nas comunidades políticas os elementos necessários à execução obediencial do poder, a exemplo do que se identifica, dentre outras, na experiência zapatista, parece ser promissor caminho para a execução da política de forma não fetichizada, não corrompida, constituindo-se como uma alternativa a ser considerada, nos países e comunidades do Sul Global.

PANSARELLI, D.; LIMA, B. R. Corruption from a Latin American perspective: the fetishization of power in the political work of Enrique Dussel. Trans/Form/Açáo, Marília, v. 45, p. 293-310, 2022. Edição Especial. 


\begin{abstract}
The purpose of this article is to present the theme of corruption, based on Enrique Dussel's political philosophy. Under the scope of the critical movements that emerge in the so-called Global South, Dussel's theoretical production aims to develop a structure that makes it possible to criticize what he calls the fetishization of power. The fetishization of power is presented as a foundation for the corruption of institutions that, unnoticed by the modern philosophical tradition, implies a political theory that legitimizes corrupted power. In our argument, we will expose the architecture of Dusselian politics, distinguishing the concepts of potentia and potestas. These concepts, in turn, allow for the differentiation between the delegated use of power and the corrupt execution of power. Then, we will make explicit the movement that Dussel assumes from Marx's critique of political economy to indicate the material content from which the critical constitution of a new political theory must be developed - content that is inspired by Latin American political experiences.
\end{abstract}

Keywords: Fetishization of power. Potentia. Potestas. Corruption. Enrique Dussel.

\title{
REFERÊNCIAS
}

CASTIANO, J. P. Referenciais da filosofia africana: em busca da intersubjetivação. Maputo: Ndjira, 2010.

DUSSEL, E. Método para una filosofía de la liberación: superación analéctica de la dialéctica hegeliana. Salamanca: Sígueme, 1974.

DUSSEL, E. Filosofía de la liberación. México: EDICOL, 1977.

DUSSEL, E. El último Marx y la liberación latinoamericana: un comentário a la terceira y cuarta redación de "El Capital”. Buenos Aires: Siglo XXI, 1990.

DUSSEL, E. 1492 - El encubrimiento del otro: Hacia el origen del "mito de la Modernidad”. La Paz: Plural, 1994.

DUSSEL, E. Ética de la liberación: en la edad de la globalización y de la exclusión. Madrid: Trotta, 1998.

DUSSEL, E. 20 tesis de política. México: Siglo XXI/CREFAL, 2006.

DUSSEL, E. Política de la libeación: Volumen I - Historia mundial y crítica. Madrid: Trotta, 2007.

DUSSEL, E. Política de la libeación: Volumen II - Arquitectónica. Madrid: Trotta, 2009.

LIMA, B. R. Fetichizaçáo do poder como fundamento da corrupçáo. Porto Alegre: Fi, 2018.

MARCOS, Subcomandante. Comunicado de enero de 2013: ellos y nosotros. Planeta Terra, 2013. Disponível em: http://enlacezapatista.ezln.org.mx/2013/01/20/ellos-ynosotros-i-lassin-razones-de-arriba/. Acesso em: 13 ago. 2020.

MARX, K. Grundrisse: manuscritos econômicos de 1857-1858: esboços da crítica da economia política. São Paulo: Boitempo, 2011. 
MARX, K. O Capital: crítica da economia política burguesa. Livro I: o processo de acumulação do capital. 2. ed. São Paulo: Boitempo, 2017.

NGOENHA, S. E. Filosofia africana: das independências às liberdades. Maputo: Edições Paulistas-África, 2003.

WEBER, M. Rejeiçóes religiosas do mundo e suas direçóes. In: WEBER, M. Textos selecionados. São Paulo: Nova Cultural, 1997 (Col. “Os Pensadores”).

Recebido: 15/8/2020

Aceito: 10/02/2021 
PANSARELLI, D.; LIMA, B. R. 